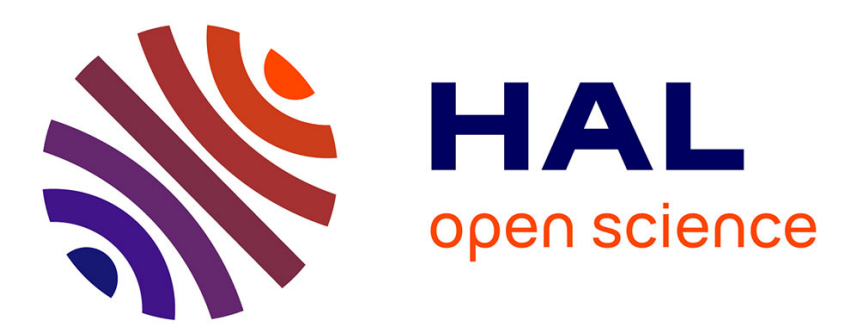

\title{
The Internal Friction Peaks in YBa2Cu3O6+x Above Room temperature Mark the Phase Transformations of the System
}

E. Bonetti, E. Campari, N. Barbagallo

\section{- To cite this version:}

E. Bonetti, E. Campari, N. Barbagallo. The Internal Friction Peaks in YBa2Cu3O6+x Above Room temperature Mark the Phase Transformations of the System. Journal de Physique IV Proceedings, 1996, 06 (C8), pp.C8-485-C8-488. 10.1051/jp4:19968105 . jpa-00254533

HAL Id: jpa-00254533

https://hal.science/jpa-00254533

Submitted on 1 Jan 1996

HAL is a multi-disciplinary open access archive for the deposit and dissemination of scientific research documents, whether they are published or not. The documents may come from teaching and research institutions in France or abroad, or from public or private research centers.
L'archive ouverte pluridisciplinaire HAL, est destinée au dépôt et à la diffusion de documents scientifiques de niveau recherche, publiés ou non, émanant des établissements d'enseignement et de recherche français ou étrangers, des laboratoires publics ou privés. 


\title{
The Internal Friction Peaks in $\mathrm{YBa}_{2} \mathrm{Cu}_{3} \mathrm{O}_{6+x}$ Above Room temperature Mark the Phase Transformations of the System
}

\author{
E. Bonetti, E.G. Campari and N. Barbagallo \\ Dipartimento di Fisica Università di Bologna and Istituto Nazionale per la Fisica della Materia, viale \\ Berti-Pichat 6/2, 40127 Bologna, Italy
}

\begin{abstract}
YBa}_{2} \mathrm{Cu}_{3} \mathrm{O}_{6+\mathrm{x}}$ system exhibits internal friction peaks above room temperature. These peaks are thermally activated. When the system is fully oxygenated $(x=1)$, one peak only is detected. At a lower oxygen content, $x<0.8$, this peak change in shape and position and a new one can be contemporarily detected. These peaks are reasonably linked with the crystal phases of the system. We present a sequence of measures taken on the same sample, where the evolution of these peaks is shown.
\end{abstract}

\section{INTRODUCTION}

The $\mathrm{YBa}_{2} \mathrm{Cu}_{3} \mathrm{O}_{6+\mathrm{x}}$ system exhibits several Internal Friction peaks, thermally activated, with energies ranging from 0.11 to $1.5 \mathrm{eV}^{1}$. Most of them are attributed to the oxygen atom motion in the $\mathrm{YBa}_{2} \mathrm{Cu}_{3} \mathrm{O}_{6+\mathrm{x}}$ basal plane ${ }^{2}$, which are proved to be the most mobile atoms in this compound by means of neutron and $\mathrm{x}$ ray diffraction data ${ }^{345}$. In this article, we will mainly discuss data taken above room temperature in the 1 $\mathrm{Hz}$ to $5 \mathrm{kHz}$ range on policrystalline samples. In these conditions 2 Internal friction peaks are measured. One of them has an activation energy of $(1.54 \pm 0.09) \mathrm{eV}$, measured on samples with an oxygen stoichiometry $x>0.8$. The other one has an activation energy of $(1.3 \pm 0.1) \mathrm{eV}$, measured on samples with $0.4<\mathrm{x}<0.6^{6}$. The peak with higher activation energy is asymmetric, expecially when measured in samples with a resonance frequency above $1 \mathrm{kHz}$, corresponding to a peak position above $650 \mathrm{~K}$. At these temperatures, under a vacuum, a fast oxygen outflow sets in ${ }^{1}$. The other peak, occurring at lower temperatures and lower oxygen content, is just an enlarged Debye peak. This enlargement has been considerd the effect of a distribution of relaxation times ${ }^{7}$.

Informations on the crystal phases were obtained by means of neutron scattering. This technique is at the same time particularly suitable to measure the sample oxygen content, since the neutron scattering length of the different atoms in the compound is in the same range, unlike that of $x$-rays. Furthermore, it gives bulk information. We will discuss in the following the behaviour of the Internal Friction peaks and present some results suggesting their energy dependence on oxygen content and crystal phase of the samples.

\section{EXPERIMENTALS}

The samples were produced by the standard solid state technique ${ }^{8}$ and pressed into bars. The process yields samples with an oxygen content around 6.9. These bars (about $1 \times 5 \times 30 \mathrm{~mm}^{3}$ ) were measured under a diffusion pump vacuum $\left(10^{-2} \mathrm{~Pa}\right)$ at temperatures up to $800 \mathrm{~K}$ by the vibrating reed tecnique with electrostatic drive and frequency modulation detection of the flexural vibration $(0.1$ to $5 \mathrm{kHz})$ of 
cantilever mounted specimens. The neutron measurements were performed with the multidetector G4.1 at the Orphée Reactor facility (LLB Saclay, France). The oxygen content of the samples was measured either by Rietveld refinement of the neutron diffraction data or by iodometric titration. A few samples were submitted to repeated thermal treatements. In these cases a dummy sample was submitted to the same treatements and used for the oxygen determination.

\section{DISCUSSION}

Soon after the discovery of the two peaks, which in the following will be referred to as $\mathrm{P}_{01}$ (the higher activation anergy peak) and as $P_{02}$, several groups reported measures in which the peak position not only changed with the resonance frequency of the sample, but also as an effect of thermal treatements, that is with the oxygen content ${ }^{1,9,10}$.This effect is shown in figure 1 which reports the results of a sequence of successive internal friction measurements on the same sample. The oxygen content in this sample (value at the beginning of each run) was measured by iodometric titration. During each run, as the temperature rises, the oxygen starts to outflow, so that we report the results of a sample with a progressively reduced oxygen content. In the oxygen rich sample (curve a) peak $P_{01}$ is strong while $P_{02}$ is a little shoulder located at its lower temperature side. In successive runs $(b, c)$, peak $P_{o 1}$ shifts towards lower temperatures and reduces in height. $P_{02}$ increases, and when the oxygen content is equal to 6.42 (d) the situation is completely reversed and $P_{01}$ is a shoulder on the high temperature side of $P_{02}$.

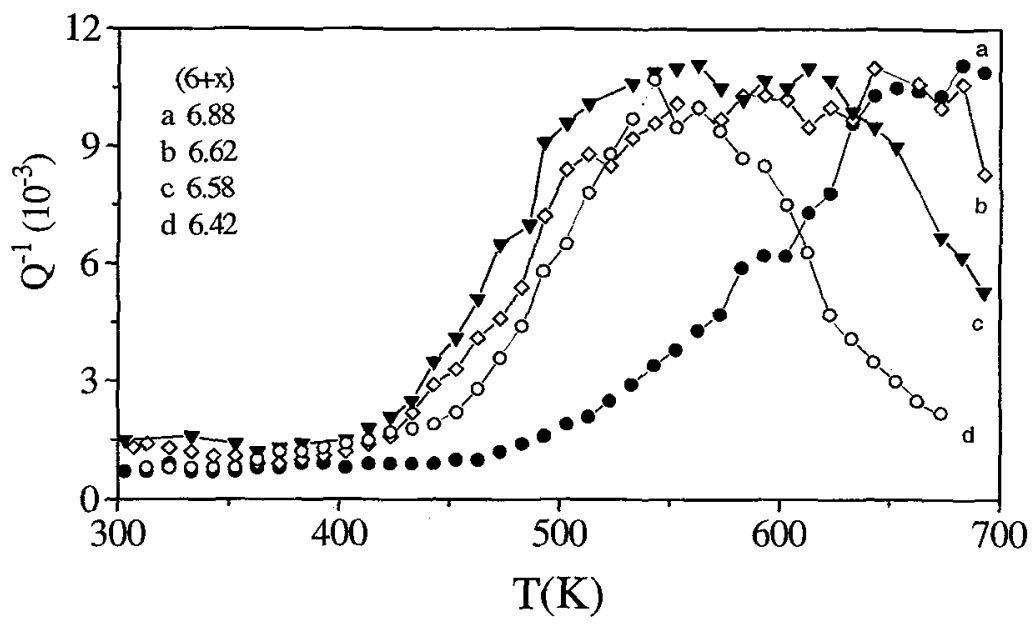

Figure 1. Sequence of Internal friction runs on the same sample. Measures under vacuum with temperature raising at 2 to $3 \mathrm{~K} / \mathrm{min}$. The oxygen content at the beginning of each run is reported inside the figure; the sample resonating frequency was $1.8 \mathrm{kHz}$. The lines are only a guide for the eye.

In all the run presented in figure 1 the temperature was raised up to about $700 \mathrm{~K}$ and then rapidly reduced because at temperatures around $700 \mathrm{~K}$ or higher the oxygen outflow (see figure 2 ) becomes increasingly fast. The oxygen outflow and the structural changes ${ }^{1}$ (basal plane oxygen desordering and orthorhombic to tetragonal transformation) that it brings about also explains the difference in shape between peak $\mathrm{P}_{\mathrm{ol}}$ and a true Debye peak, when measured at frequency of $1 \mathrm{kHz}$ or higher. In fact, the same peak is closer to a Debye peak when measured at frequencies in the $10 \mathrm{~Hz}$ range. 
The idea that $P_{o 1}$ shifts with the oxygen content is also conceived by the isothermal measurements that we performed under vacuum on oxygen rich samples. One of them is reported in figure 3, together with a fit obtained using an activation energy varying with time: $\mathrm{H}(\mathrm{t})=\mathrm{H}_{\max }-\alpha t$. In this case the well known formula for a Debye peak becomes:

$$
Q^{-1}=\Delta \frac{A \exp (-t / \tau)}{1+A^{2} \exp (-2 t / \tau)}
$$

where $\Delta$ is the peak strength, $\tau=k T / \alpha, A=\omega \tau_{0} \exp \left(\mathrm{H}_{\max } / \mathrm{kT}\right)$ and $\alpha$ is a constant. The time dependence of the activation energy has been taken linear because a $10 \%$ shift in $\mathrm{H}$ is enough to reduce the peak intensity from its maximum value to the background. The existence of two orthorhombic phases ${ }^{10}$ in this system is, according to us, a reasonable starting point to explain the presence and behaviour of these peaks. In oxygen rich samples $(x>0.9)$, what is usually observed is the presence of the so called orthorhombic I phase (and of the tetragonal phase at temperatures above $700 \mathrm{~K}$, depending on the sample and the exact oxygen content). At lower oxygen contents becomes stable, in the low temperature range, the other orthorhombic phase ", which differs from the previous one for the oxygen atoms in the basal plane are aligned in every other line along the $b$

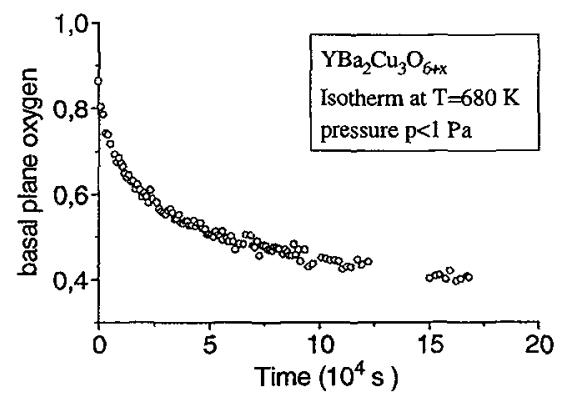

Figure 2. Basal plane oxygen content as a function of time as measured by Rietveld refinement of neutron scattering data. Isothermal measure at $\mathrm{T}=680 \mathrm{~K}$ under vacuum.

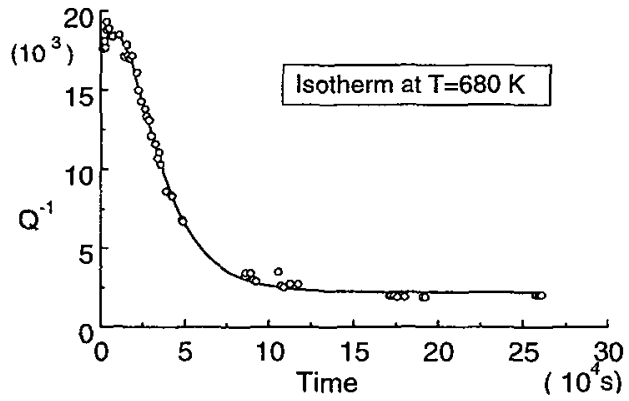

Figure 3 Internal Friction of a sample, produced with $x>0.9$ as a function of time during an isothermal test at $680 \mathrm{~K}$ under vacuum. The line is a fit of the data using eq. 1.

axis. We suggest that $P_{o 1}$ is the peak due to the motion of oxygen atoms between positions $(1 / 2$, $0,0)$ and $(0,1 / 2,0)$ in the orthorhombic I phase and $P_{o 2}$ the same peak relative to the orthorhombic II phase.The same kind of atomic motion has an obvious energy difference in the two crystal arrangements, as is measured for $P_{o 1}$ and $P_{02}$. Furthermore, as reported in figure 4 and 5 , it is also observed that in samples with increasingly less oxygen, the $a$ and $b$ axes length change and so does the $(1 / 2,0,0)$ and $(0,1 / 2,0)$ site occupancy. This agrees well with the idea of a changing activation energy, that is of a shift of $\mathrm{P}_{01}$. The activation energy should have a maximum when $\mathrm{x}=1$ (orthorhombic $\mathrm{I}$ ) and should progressively decrease towards the value of the orthorhombic II phase. As orthorhombic I samples with less oxygen are considered, the oxygen atomic jumps which give rise to $P_{o 1}$ occurrs between site whose energy difference is changing; furthermore part of the sample has turned into a new phase (orthorhombic II).

Various calculations ${ }^{1,8,12}$ based on the jumping of the oxygen atoms between $(1 / 2,0,0)$ and $(0,1 / 2,0)$ sites and neutron diffraction results ${ }^{13}$, suggest that the $P_{01}$ strength should increase with the oxygen decrease. The experimental results show a more complex behaviour. Both $\mathrm{P}_{\mathrm{o} 1}$ and $\mathrm{P}_{\mathrm{o} 2}$ 


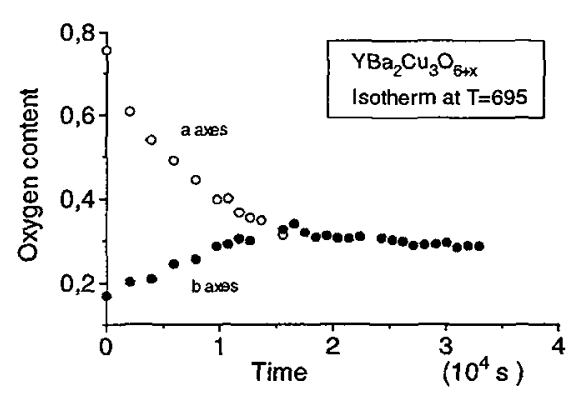

Figure 4. Oxygen content for the $(1 / 2,0,0)$ and $(0,1 / 2,0)$ sites as a function of time. Data obtained from a Rietveld refinement of neutron scattering of an $\mathrm{YBa}_{2} \mathrm{Cu}_{3} \mathrm{O}_{6+\mathrm{x}}$ sample kept under vacuum at $695 \mathrm{~K}$.

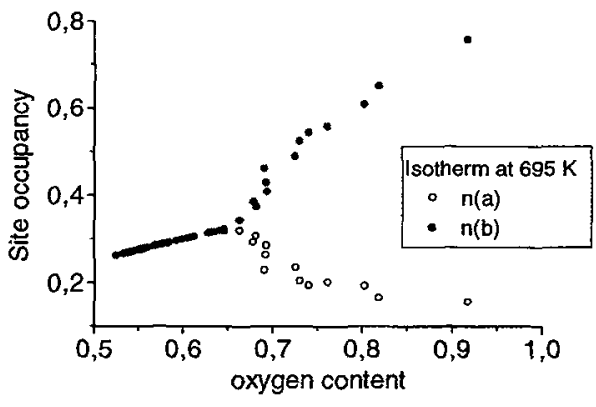

Figure 5. $(1 / 2,0,0)$ and $(0,1 / 2,0)$ site occupancy ( $n(a)$ and $n(b)$ ) on the same sample of figure 4 as a function of the overall basal plane oxygen content.

independently raise and fall in strength as a function of the oxygen content. Usually the value measured for $\mathrm{P}_{02}$ at its optimum oxygen concentration $(x=0.5)$ is greater than that for $P_{01} \quad(x=1)$. This could be well the result of the balancing of at least three parameters: oxygen content, oxygen occupancy of the $(1 / 2,0,0)$ and $(0,1 / 2,0)$ sites and relative proportion of the two orthorhombic phases. Finally, $\mathrm{P}_{02}$ do not show a shift in position as clear as in the case of $\mathrm{P}_{01}$. It is true anyway that the changes occurring in the orthorhombic II phase as a function of the oxygen content are smaller than that occurring in the orthorhombic I phase and this could explain the difference.

\section{REFERENCES}

${ }^{1}$ E.Bonetti, E.G.Campari, M.D'Astuto, M.Marangolo: Phys. Rev. B 51(1995), 1249

${ }^{2}$ Crystal structures of the High- $\mathrm{T}_{\mathrm{c}}$ superconducting copper-oxides. Elsevier science (Amsterdam, The Netherlands, 1994)

${ }^{3}$ D.Woirgard, A.Riviere: Europhysics Lett. 17 (1992),601

${ }^{4}$ J.D.Jorgensen, B.W.Veal, A.P.Paulikas, L.J.Nowicki, G.W.Crabtree, H.Claus, W.K.Kwok: Phys. Rev. B 41 (1990), 1863

${ }^{5}$ G. van Tendeloo, D.Bıoddin, H.W.Zandbergen, S.Amelinckx: Physica C 167 (1990),627

${ }^{6}$ E.Bonetti, E.G.Campari, S.Mantovani: Physica C 196 (1992),7

${ }^{7}$ J.R.Cost and J.T.Stanley: J. Mater. Res. 6 (1991), 232

${ }^{8}$ E.Bonetti, E.G.Campari, A.Casagrande, S.Mantovani: in High temperature superconductivity,. edited by C.Ferdeghini, A.S.Siri. World Scientific Publishing (Singapore, 1990), p. 223

${ }^{9}$ G.Cannelli, R.Cantelli, F.Cordero, F.Trequattrini, S.Ferraro, M.Ferretti: Solid state Comm. 80 (1991),715

${ }^{10}$ X.M.Xie, T.G.Chen: Supercond. Sci. Technol. 5 (1992),290

${ }^{11}$ G.Ceder, M.Asta, D.de Fontaine: Physica C 177 (1990),106

${ }^{12}$ A.S.Nowick, B.S.Berry: Anelastic relaxation in crystalline solids. Academic Press (New York, 1972)

${ }^{13}$ J.D.Jorgensen, M.A.Beno, D.G.Hinks, L.Soderholm, K.J.Volin, R.L.Hitterman, J.D.Grace, I.K.Shuller, C.U.Segre, K.Zhang, M.S.Kleefish: Phys. Rev. B 36 (1987),3608 